\title{
PRIBAVLJANJE I OTUĐENJE OSNOVNIH SREDSTAVA U PRIVREDI
}

\section{REZIME}

Finansijski lizing predstavlja specifičan oblik nabavke osnovnih sredstava. Davalac lizinga finansira nabavku sredstava od proizvođača za potrebe primaoca lizinga. Primalac lizinga za uzvrat plaća davaocu lizinga naknadu, najčešće u ratama. Lizing rata sadrži otplatu obaveze prema lizing društvu i kamatu za korišćenje finansijskih sredstava davaoca lizinga. Nabavljeno sredstvo primalac lizinga evedentira u finansijskim izveštajima kao sopstveno sredstvo koje podleže amortizaciji

Ključne reči: finansijski lizing, primalac lizinga, davalac lizinga

\section{UVOD}

Privredni subjekti mogu finansirati osnovna sredstva na različite načine: iz sopstvenih izvora, pomoćubankarskih kredita ili putem lizinga. Finansiranje nabavke putem lizinga pruža brojne prednosti. Korisnik lizinga prilikom nabavke ne plaća pun iznos nabavne vrednosti, već naknadu za zakupljeno sredstvo isplaćuje u ratama. Po isteku ugovorenog perioda, zakupac može da otkupi iznajmljeno sredstvo po znatno nižoj ceni, ili da uzme u zakup novo i savremenije sredstvo. Prednost zakupa ogleda se i u izbegavanju rizika po osnovu vlasništva nad sredstvom, kao što su gubitatak ili tehničko-tehnološka zastarelost sredstva. Iz navedenih razloga, lizing postaje sve češći oblik pribavljanja osnovnih sredstava.

Lizing je ugovor kojim davalac lizinga prenosi na korisnika lizinga pravo korišćenja nekog sredstva na odreneno vreme i uz odgovarajuću naknadu. Postoje dve vrste lizinga: finansijski i operativni. Osnovna razlika izmenu finansijskog i operativnog lizinga ogleda se u prenošenju vlasništva nad predmetom lizinga na korisnika lizinga na kraju ugovorenog perioda. Kod finansijskog lizinga, vlasništvo nad predmetom lizinga prenosi se na korisnika lizinga po isteku perioda otplate, dok se kod operativnog lizinga nepodrazumeva prenos vlasništva.

\section{PRIBAVLJANJE OSNOVNIH SREDSTAVA}

Proces ulaganja u osnovna sredstva odvija se kroz dve posebno odvojene faze i obe su predmet knjigovodstvenog obuhvatanja. Prva faza predstavlja kupovinu kao i prijem materijalnih vrednosti dok druga faza predstavlja isplatu obaveza za nabavljenim sredstvima. Obe ove faze čine celinu procesa ulaganja novca u osnovna sredstva i ostale faktore proizvodnje. Zbog toga se kupovina tj. prijem i novčani izdatak u knjigovodstvu prikazuju paralelno. Preduzeća svoja osnovna sredstva (stvari i prava ) mogu pribavljati na tri načina a to su ${ }^{58}$ :

- Kupovina

- Besplatni prijem - prijem bez naknade

- Izgradnja

- Utvrđivanje viškova pri inventarisanju

Za sva četiri pomenuta načina nabavke osnovnih sredstava isplata se može izvršiti sa: tekućeg računa; iz izdvojenih novčanih sredstava za investicije; iz odobrenih zajmova; kombinovano iz prethodnih izvora.

Za evidenciju svih osnovnih sredstava iz kojih se izuzimaju zemljišta, šume, višegodišnji zasadi i osnovna stada knjigovodstvo svakog preduzeća koristi dva paralelna računa. Na prvom od ovih paralelnih racuna treba obezbediti sve neophodne podatke o nabavnoj vrednosti, dok na drugom računu treba obezbediti podatke o otpisanoj vrednosti konkretne vrste sredstava. $\mathrm{Na}$ osnovu ovako tačno evidentiranih paralelnih računa knjigovodstvo je u mogućnosti da obračuna i treću vrednost ovih osnovnih sredstava, a to je sadašnja vrednost.

\footnotetext{
56 Univerzitet za poslovne studije, Banja Luka

${ }^{57}$ Visoka škola za menadzment i ekonomiju, Kragujevac

${ }^{58}$ Milojević I., Računovodstvo, Centar za ekonomska i finansijska istraživanja, Beograd, 2010. god., str. 168.
} 


\subsection{Kupovina osnovnih sredstava}

Kupovina osnovnih sredstava je najčešći oblik pribavljanja, i time se zamenjuju dotrajala sredstva i proširuju postojeći kapaciteti. Kod ulaganja u osnovna sredstva, trošak nabavke čini njihova nabavna vrednost koja obuhvata fakturnu vrednost dobavljača uvećanu za zavisne troškove nabavke (ZTN) i umanjeno za eventualni trgovinski popust i rabat. Ulaganja u osnovna sredstva putem kupovine podrazumeva :

- Kupovinu novih osnovnih sredstava

- Kupovinu korišćenih osnovnih sredstava

1) Kupovina novih osnovnih sredstava

Preduzeće može nabaviti sredstva koja se odmah mogu uključiti u upotrebu ili sredstva kojima se npr. mora prvo izgraditi postrojenje, izraditi priključak na električnu energiju ili gas, izvršiti montaža, itd.

Knjiženje kupovine novih osnovnih sredstava vrši se iz tri faze.

U prvoj fazi se zadužuju računi: Nekretnine, postojenja i oprema u pripremi za nabavnu vrednost osnovnog sredstva i zavisne troškove nabavke (ZTN), s tim što se odvojeno knjiži u stavovima navavna vrednost i ZTN, i račun PDV u primljenim fakturama, za iznos obračunatog Poreza na dodatu vrednost po propisanoj stopi. Istovremeno se odobrava račun Dobavljača za nabavnu vrednost i ZTN (odvojeno) sa PDV-om.

U drugoj fazi se zadužuju Dobavljači za nabavnu vrednost i ZTN sa PDV-om a odobrava Tekući račun ili Izvojeni akreditivi ukoliko je prethodno otvoren akreditiv, ili Dugoročni kredit, u zavisnosti od toga iz kojih sredstava je izvršena isplata.

U trećoj fazi se vrši aktiviranje tj. stavljanje u upotrebu time što se zadužuje račun Nekretnina, postrojenja i opreme a odobrava i gasi račun Nekretnina, postrojenja i opreme u pripremi za isti iznos.

2) Kupovina korišćenih osnovnih sredstava

Preduzeća mogu na tržištu kupiti i već korišćena osnovna sredstva. Vrednost korišćenih sredstava određuje ponuda i tražnja na tržištu a ne neotpisana vrednost po kojoj se vode u knjigovodstvu prodavca, pa otuda njihova kupovna tržišna vrednost može biti viša, niža ili jednaka neotpisanoj vrednosti. Ukoliko bi preduzeće kupac kao nabavnu vrednost vodilo tržišnu vrednost (vrednost po kojoj je kupilo sredstvo), bilo bi povređeno načelo jasnosti jer bi podaci o samo nabavnoj vrednosti bez podataka o otpisanoj onemogućili procenu stepena otpisanosti sredstava i moglo bi se zaključiti da se radi o novom sredstvu. Otuda pri knjigovodstvenom obuhvatanju nabavke korišćenih sredstava treba zadržati prvobitnu nabavnu vrednost kao a kupovnu vredsnost treba smatrati kao neotpisanu, sadašnju vrednost.

Knjiženje korišćenih osnovnih sredstava vrši se tako što se zaduže računi: Nekretnine, postrojenja i oprema za prvobitnu nabavnu vrednost i PDV u primljenim fakturama za obračunati poren na kupovnu vrednost; a odobre računi: Dobavljači za kupovnu vrednost sa PDV-om i Ispravka vrednosti osnovnih sredstava za razliku između prvobitne nabavne i kupovne vrednosti.

Isplata prilikom ove kupovine se vrši isto kao i kod kupovine novog sredstva.

\subsection{Besplatni prijem}

Evidentiranje u poslovnim knjigama računovodstva u vezi sa pribavljanjem osnovnih sredstava prijemom bez naknade najčešće se javlja prilikom osnivanja preduzeća, kada osnivač besplatno obezbeđuje sredstva u obliku stvari za korišćenje. U toku poslovanja isto može doći do prijema sredstva od strane osnivača ili drugih organizacija. Prijem se vrši na osnovu ugovora koji se sklapa između preduzeća ustupaoca i preduzeća primaoca sredstava, i na osnovu odluke organa upravljanja. Prilikom prijema sredstva se moraju pregledati i proceniti a evidencija sredstava se vrši po prvobitnoj nabavnoj vrednosti. Preduzeće može primiti osnovno sredstvo po kome postoji obaveza na neotplaćeni kredit i u tome slučaju može prihvatiti i obavezu otplate duga, za šta je potrebna i saglasnot poverioca (banke).

U zavisnosti od toga da li se radi o statusnoj promeni ili donaciji, knjiženje prijema na poklon vrši se tako što zadužujemo odgovarajući račun - Nekretnine, postrojenja i oprema, za iznos nabavne vrednosti, a odobravamo odgovarajući račun - Ispravka vrednosti osnovnih sredstava, za iznos otpisane vrednosti, i račun - Ostali prihodi (ukoliko je donacija) ili Kapital (ukoliko je statusna promena), za iznos sadašnje neotpisane vrednosti.

Ukoliko preduzeće prijemom preuzima obavezu vraćanja dugoročnog ili kratkoročnog kredita, takođe će se odobriti i odgovarajući račun za preuzeti iznos.

\subsection{Izgradnja osnovnih sredstava}

Ulaganje u osnovna sredstva putem izgradnje za svako preduzeće predstavlja složen poslovni poduhvat i sa tehničko-tehnološkog i sa ekonomskog aspekta. Odnosni se uglavnom na izgradnju 
građevinskih objekata kod kojih je pre ulaganja potrebno ivršiti proračun ekonomske opravdanosti u takvo ulaganje. Visina potrebnih novčanih sredstava određuje se na osnovu podataka sadržanih u investicionom programu i tehničkoj dokumentaciji. $U$ odluci organa upravljanja mora biti navedena predračunska vrednost građevinskih objekata, opreme, visina troškova montaže, opreme i drugih izdataka u vezi sa izgradnjom i puštanjem u rad datog objekta, kao i izvori iz kojih su obezbeđena sredstva za finansiranje izgradnje. Pribavljanje građevinskih objekata obično se vrši:

1) izgradnjom u tuđoj, ili

2) izgradnjom u sopstvenoj režiji.

1) Izgradnja u tuđoj režiji

U izgradnji objekata pojavljuju se sledeća lica: izvođač radova - građevinsko preduzeće, investitor - organizacija za koju se radovi izvode i banka kao kreditor, ukoliko preduzeće nema dovoljno sopstvenih sredstava.

Izvođači radova obično ne raspolažu obrtnim sredstvima koja bi bila dovoljna za otpočinjanje radova, pa je običajeno avansno plaćanje (plaćanje unapred) obaveza. Obračun radova se obavlja podnošenjem situacija koje predstavljaju fakture izvođača radova. Te situacije mogu biti: privremene (obračunske), koje se podnose u toku radova, i konačne, koje se podnose po završetku radova.

Tokom izgradnje, po prijemu situacija vrši se knjiženje objekta u pripremi dok se aktiviranje sprovodi nakon dobijanja dozvole nadležnog organa lokalne samouprave o upotrebi objekta.

Knjiženje izgradnje osnovnih sredstava u tuđoj režiji sastoji se iz pet faza.

U prvoj fazi se zadužuje račun Izdvojena novčana sredstva za investicije a odobrava Tekući račun, za izdvojena sredstva unapred ukoliko je preduzeće tako planiralo.

U drugoj fazi se izplaćuje avans izvođaču radova time što se zaduži račun Avansi, ukoliko je tako ugovoreno sa izvođačpm radova, a odobri račun Izdvojena novčana sredstva za investicije, ukoliko je preduzeće prethodno izdvojilo sredstva, ili Tekući račun.

$\mathrm{U}$ trećoj fazi se primaju privremene i konačne situacije od izvođača radova i zadužujemo račun Investicione nekretnine u pripremi, za iznos ispostavljene prve privremene situacije a kod drugih i ostalih za iznos razlike ispostavljenih i proknjiženih prethodnih građevinskih situacija, i PDV u primljenim fakturama po odgovarajućoj stopi, a odobravamo račun Dobavljači za iznos faktura sa PDV-om.

$\mathrm{U}$ četvrtoj fazi isplaćujemo obavezu prema izvođaču radova, i zadužujemo Dobavljače za ukupan iznos sa PDV-om a odobravamo Avanse, Tekući račun ili Dugoročni krediti, u zavisnosti od načina plaćanja.

U poslednjoj fazi se objekat stavlja u upotrebu i zadužujemo Građevinske objekte, za ukupnu vrednost građevinskih objekata koja se aktivira, a odobravamo Investicione nekretnine u pripremi za isti iznos.

2) Izgradnja u sopstvenoj režiji

Ukoliko preduzeće ima sopstvenu opremu i kadrove, može za svoje potrebe graditi objekte pod uslovom da njihova predračunska vrednost ne prelazi limit određen zakonom. Kao izvođač radova najčešće se javlja posebna radna jedinica koja već posluje u preduzeću koje je investitog, pa se tako stiču prihodi od aktiviranja sopstvenih učinaka. $S$ obzirom da se radi o realizaciji unutar jedne organizacije, kao prodajna cena mose se priznati samo iznos izvršenih ulaganja, a ne i eventualni finansijski dobitak. U vrednost objekta ulazi i cena projektne dokumentacije kao i upotrebna dozvola i uknjižavanje objekta.

Knjiženje izgradnje u sopstvenoj režiji vrši se u četiri faza.

$U$ prvoj fazi zadužujemo Investicione nekretnine u pripremi i PDV u primljenim fakturama, a odobravamo Dobavljače za iznos fakture sa PDV-om, čime se vrši nabavka projektne dokumentacije.

U drugoj fazi se knjiži izgradnja objekta po podacima iz pogonskog knjigovodstva i zadužuje račun Investicione nekretnine u pripremi, za iznos ukupne vrednosti objekta a odobrava račun Prihodi od aktiviranja proizvoda i usluga za sopstvene potrebe, za isti iznos.

U trećoj fazi se isplaćuje upotrebna dozvola i zadužuje račun Investicione nekretnine u pripremi a odobrava Tekući račun.

U četvrtoj fazi se objekat stavlja u upotrebu i zadužuje račun Građevinski objekti a odobrava račun Investicione nektretnine u pripremi za ukupnu vrednost objekta.

\subsection{Utvrđivanje viškova pri inventarisanju}

Popisom osnovnih sredstava na kraju poslovne godine ili prilikom vanrednog popisa $u$ toku godine, moguće je utvrditi da se određena osnovna sredstva nalaze u upotrebi, a da nisu iskazana u knjigovodstvu osnovnih sredstava. Takva sredstva se naknadno iskazuju u knjigovodstvu, na osnovu zapisnika popisu, po vrednostima utvrđenih procenom od strane stručne komisije. Procenom se utvđuje nabavna i otpisana vrednost, i po procenjenoj vrednosti se iskazuju osnovna sredstva u knjigovodstvu. 
Višak osnovnih sredstava vrši se zaduženjem računa Osnovna sredstva, za procenjenu nabavnu vrednost, a odobravaju računi: Ispravka vrednosti osnovnih sredstava, za procenjenu otpisanu vrednost i Viškovi, za iznos razlike između procenjene nabavne i otpisane vrednosti.

\section{OTUĐENJE OSNOVNIH SREDSTAVA}

Preduzeća mogu otuđiti osnovna sredstva na sledeće načine ${ }^{59}$ :

- Prodajom

- Besplatnim ustupanjem

- Rashodovanjem (otpisom)

- Utvrđivanjem manjkova pri inventarisanju

U svakom od ovih slučajeva mora postojati odluka organa upravljanja kao dokument na osnovu kojeg se osnovna sredstva isknjižavaju iz evidencije. Uz odluku treba da postoji i faktura, ako se sredstvo prodaje, ili zapisnik o prodaji rashodovanog sredstva. Osnovna sredsta se izbacuju iz upotrebe najčešće zbog njihove fizičke istrošenosti ili tehničke odnosno ekonomske zastarelosti. Osnovna sredstva koja se nalaze van upotrebe i koja su neupotrebljiva, na osnovu organa upravljanja mogu se: prodati, ustupiti bez naknade ili otpisati.

\subsection{Prodaja osnovnih sredstava}

Preduzeće može prodati osnovno sredstvo drugom pravnom licu, po ceni koja je:

- jednaka neamortizovanoj vrednosti,

- manja od neamortizovane vrednosti, ili

- veća od neamortizovane vrednosti.

Ako je prodajom postignuta prodajna cena veća od njegove sadašnje vrednosti, javlja se pozitivna razlika, koja za preduzeće predstavlja kapitalni dobitak koji se klasifikuje kao ostali prihod na računu 670 - Dobici od prodaje nematerijalnih ulaganja, nekretnina, postrojenja i opreme. Ukoliko je postignuta prodajna cena niža od njegove sadašnje vrednosti vrednosti, javlja se negativna razlika, koja se iskazuje kao ostali rashod na računu 570 - Gubici po osnovu rashodovanja i prodaje nematerijalnih ulaganja, nekretnina, postrojenja i opreme.

Knjiženje prodaje osnovnih sredstava u poslovnim knjigama preduzeća vrši se iz dve faze.

U prvoj fazi se zadužuju računi: Kupci, za iznos prodajne vrednosti sa PDV-om, Ispravka vrednosti osnovnih sredstava, za iznos otpisane vrednosti i Gubici po osnovu rashodovanja i prodaje nematerijalnih ulaganja, nekretnina, postrojenja i opreme, ukoliko je prodajna cena manja od neamotizovane (sadašnje) vrednosti i Dugoročni krediti, ukoliko se na osnovu ugovora ustupa obaveza otplate dugoročnog kredita. Istovremeno se odobravaju računi: Osnovna sredstva, za iznos nabavne vrednosti osnovnih sredstava, PDV u izdatim fakturama, za iznos PDV-a i Dobici od prodaje nematerijalnih ulaganja, nekretnina, postrojenja i opreme, ukoliko je prodajna cena veća od neamotizovane vrednosti.

U drugoj fazi se knjiži naplata potraživanja tako što se zaduži račun Tekući račun a odobro račun Kupci, za iznos naplaćenog potraživanja

\subsection{Besplatno ustupanje}

Preduzeće obično besplatno ustupa sredstva koja su upotrebljavana, ali ne i amortizovana u potpunosti. To preduzeće nema obavezu nadoknađivanja neamortizovane vrednosti ukoliko ga je ustupilo drugom preduzeću na korišćenje, ali može preneti obavezu otplate dugoročnog kredita.

Knjiženje besplatnog ustupanja se vrši se zaduženjem računa: Ispravka vrednosti osnovnih sredstava, za iznos otpisane vrednosti, Ostali rashodi, za iznos koji predstavlja razliku između nabavne i otpisane vrednosti uvećanu za PDV, i račun Dugoročni krediti, ukoliko je ustupljena obaveza otplate kredita; a odobrenjem računi: Osnovna sredstva za iznos nabavne vrednosti sredstva i PDV u izdatim fakturama, za iznos PDV-a koji se obračunava na iznos rashoda.

\subsection{Rashodovanje osnovnih sredstava}

Rashodovanje ili likvidacija osnovnih sredstava predstavlja postupak izbacivanja iz upotrebe konkretnih osnovnih sredstava, zbog fizičke dotrajalosti, tehničke i moralne zastarelosti i sl. jer sredstva postaju neupotrebljiva. Mogu se rashodovati potpuno otpisana i delimično otpisana sredstva.

\footnotetext{
59 Milojević I., Računovodstvo, Beograd 2010. god., str. 174.
} 
Knjiženje rahodovanja se vrši tako što se zaduže računi: Ispravka vrednosti osnovnih sredstava, za iznos otpisane vredsnosti, i Gubici po osnovu rashodovanja, ukoliko se rahoduje delimično otpisano sredstvo, a odobri račun Osnovna sredstva, za iznos nabavne vrednosti.

\subsection{Manjkovi osnovnih sredstava}

Manjak predstavlja oblik otuđenja imovine i zbog toga ona treba da se isknjiži iz finansijskih izveštaja. Može se utvrditi redovnim ili vanrednim popisom, a nakon toga je potrebno isknjižiti osnovno sredstvo. Manjak se knjigovodstveno ovuhvata u visini sadašnje vrednosti, na šta se obračunava i PDV. Za nastali manjak se može teretiti lice za koje se dokaže da je uticalo na nastanak manjka, teretiri konto rashoda preduzeća ili deo na teret lica a ostatak na teret preduzeća.

Knjiženje manjkova se vrši tako što se zaduže računi: Ispravka vrednosti osnovnih sredstava, za iznos otpisane vrednosti sredstva, i Manjkovi, za iznos razlike između nabavne i otpisane vrednosti sredstava uvećane za PDV, ukoliko je manjak pripisan rashodima preduzeća, ili Potraživanja od zaposlenih, za iznos razlike između nabavne i otpisane vrednosti sredstava uvećane za PDV, ukoliko je manjak pripisan na teret odgovornog lica; a odobre računi: Osnovna sredstva, za iznos nabavne vrednosti, i Obaveze za PDV, za iznos PDV-a obračunat na razliku između nabavne i otpisane vrednosti.

\section{ZAKLJUČAK}

Računovodstveno obuhvatanje nabavke osnovnih sredstava putem finansijskog lizinga slično je knjiženju nabavke sredstava na kredit. Prednosti lizinga u odnosu na kredit su brža realizacija procesa finansiranja, niže kamatne stope, manje garancije (predmet lizinga je sredstvo osiguranja) i poreske olakšice (obračunata amortizacija smanjuje oporezivi profit).

Korisnik lizinga priznaje sredstvo, koje je predmet lizinga, kao imovinu i kao obavezu u bilansu stanja, iako formalno nije vlasnik sredstva. Naknada koju korisnik lizinga plaća davaocu lizinga sadrži nabavnu vrednost sredstva i kamatu. Naknada se isplaćuje u ratama, najčešće mesečno. Isplatom poslednje rate, korisniklizinga postaje vlasnik sredstva.

\section{LITERATURA}

1. Ćirović R., (2007) PDV na finansijski i operativni lizing, Privredni savetnik, Beograd, Savez

2. računovona i revizora Srbije

3. Grupa autora, (2007) Priručnik o primeni kontnog okvira u skladu sa MRS/MSFI, Beograd, Savez računovona i revizora Srbije

4. Milojević I., Računovodstvo, Centar za ekonomska i finansijska istraživanja, Beograd, 2010.

5. Petrović Z, Rakočević .., (2004) Priručnik za primenu MRS, Beograd, IPC

6. Stojanović, R., (2007) Finansijsko izveštavanje, Beograd, Savez računovona i revizora Srbije

7. Stojanović R, Čanak J, Škobić Z., (2006) Računovodstvene politike, Beograd, Savez računovona i

8. revizora Srbije

9. Tatić I., (2006) Ugovor o lizingu kao način finansiranja nabavke opreme, VI seminar - Primena

\section{ABSTRACT}

Financial leasing represents a specific form of purchasing fixed assets. The lessor finances the purchase of assets from a manufacturer for the lessee's needs. The lessee in turn pays a rent to the lessor, usually divided into installments. A leasing installment consists of paying the principal to the leasing company as well as the interest for using the funding. The purchased assets are registered in the lessee's financial reports as their asset which is to be amortized.

Key words: financial leasing, lessee, lessor. 